\title{
Priming letters by colors: evidence for the bidirectionality of grapheme-color synesthesia
}

Article

Published Version

Weiss, P., Kalckert, A. and Fink, G. (2009) Priming letters by colors: evidence for the bidirectionality of grapheme-color synesthesia. Journal of Cognitive Neuroscience, 21 (10). pp. 2019-2026. ISSN 1530-8898 doi:

https://doi.org/10.1162/jocn.2008.21166 Available at https://centaur.reading.ac.uk/69614/

It is advisable to refer to the publisher's version if you intend to cite from the work. See Guidance on citing.

Published version at: http://www.mitpressjournals.org/doi/abs/10.1162/jocn.2008.21166\#.WMoKqIV96Uk

To link to this article DOI: http://dx.doi.org/10.1162/jocn.2008.21166

Publisher: MIT Press

All outputs in CentAUR are protected by Intellectual Property Rights law, including copyright law. Copyright and IPR is retained by the creators or other copyright holders. Terms and conditions for use of this material are defined in the End User Agreement.

www.reading.ac.uk/centaur 
Central Archive at the University of Reading

Reading's research outputs online 


\title{
Priming Letters by Colors: Evidence for the Bidirectionality of Grapheme-Color Synesthesia
}

\author{
Peter H. Weiss ${ }^{1}$, Andreas Kalckert ${ }^{1}$, and Gereon R. Fink ${ }^{1,2}$
}

\begin{abstract}
In synesthesia, stimulation of one sensory modality leads to a percept in another nonstimulated modality, for example, graphemes trigger an additional color percept in graphemecolor synesthesia, which encompasses the variants letter-color and digit-color synesthesia. Until recently, it was assumed that synesthesia occurs strictly unidirectional: Although the perception of a letter induces a color percept in letter-color synesthetes, they typically do not report that colors trigger the percept of a letter. Recent data on number processing in syn-
\end{abstract}

\section{INTRODUCTION}

In synesthesia, stimulation of one sensory modality results in an additional percept either within the same sensory modality or in a different, nonstimulated one. The most studied form of synesthesia, grapheme-color synesthesia, which encompasses the variants lettercolor and digit-color synesthesia, has a prevalence of about $2 \%$ in the population (Simner et al., 2006). In grapheme-color synesthesia, the presentation of a grapheme leads to an additional synesthetic color percept, which may interfere with the visual processing of the grapheme color (Weiss, Zilles, \& Fink, 2005; Mattingley, Rich, Yelland, \& Bradshaw, 2001). Although grapheme-color synesthetes are strongly influenced by the synesthetic color perception triggered by a specific grapheme (Callejas, Acosta, \& Lupianez, 2007), they usually do not report that a color triggers the perception of a specific grapheme. Accordingly, in the majority of cases, synesthesia has long been considered unidirectional with the inducer (here: grapheme) eliciting the perception of the concurrent (here: color), but not vice versa (however, see Cohen Kadosh, Cohen Kadosh, \& Henik, 2007).

Recent research, however, challenges this principle of unidirectionality (Knoch, Gianotti, Mohr, \& Brugger, 2005; Cohen Kadosh \& Henik, 2006b; Simner \& Hubbard, 2006; Cohen Kadosh et al., 2005; Brugger, Knoch, Mohr, \& Gianotti, 2004). Recently, Simner and Hubbard (2006)

\footnotetext{
${ }^{1}$ Research Center Jülich, Germany, ${ }^{2}$ Cologne University Hospital, Cologne, Germany
}

esthesia suggest, however, that colors can implicitly elicit numerical representations in digit-color synesthetes, thereby questioning unidirectional models of synesthesia. Using a word fragment completion paradigm in 10 letter-color synesthetes, we show here for the first time that colors can implicitly influence lexical search. Our data provide strong support for a bidirectional nature of grapheme-color synesthesia and, in general, may allude to the mechanisms of cross-modality interactions in the human brain. provided behavioral evidence for implicit connections between the two types of concurrents (colors and personalities) in A. P., a woman with both grapheme-color synesthesia and ordinal linguistic personification synesthesia. In three digit-color synesthetes, Brugger et al. (2004) were able to elicit an effect comparable to the spatial-numerical association of response codes (SNARC) effect (Dehaene, 1992) by presenting colors instead of numbers. The left-hand responses of the synesthetes were faster for colors representing a small number, whereas their right-hand responses were faster to colors representing large numbers. This effect was not observed in nonsynesthetic control subjects, who had previously learned similar digit-color associations. These findings, therefore, suggested an (implicit) coactivation of the number magnitude representation by color in digit-color synesthesia. Using a color-modified version of the Mental Dice Task, in which a random sequence of colors instead of numbers had to be generated, Knoch et al. (2005) found a similar effect: Their 20 digit-color synesthetes showed a pattern as if they had played dice with numbers (too few repetitions, too many counts). The authors proposed that in naming the respective colors, an "automatic coactivation of relational properties of numbers" occurs (p. 373). These data suggest that digit-color synesthesia is, at least implicitly, bidirectional. This notion has been supported by further case studies. Cohen Kadosh et al. (2005) found in two digit-color synesthetes that colors can facilitate numerical magnitude judgments in a modified size congruity paradigm, in which the irrelevant dimension of physical size was replaced by that of color. Finally, the digit-color synesthete I. S. was 
clearly slower in indicating which of two lines was longer when the longer line was colored with an incongruent color corresponding to a small number (Cohen Kadosh \& Henik, 2006b). When the line was colored with the congruent color, reaction times of I. S. were comparable to those of eight nonsynesthetic control subjects. Thus, Cohen Kadosh and Henik (2007) suggest that the concurrent (here: color) can trigger the representation of the inducer digit even in the absence of a physically presented digit.

Most of the abovementioned studies on digit-color synesthesia utilized the correspondence between numerical magnitude and spatial attributes. To the best of our knowledge, no study exists to date which investigates the notion of bidirectionality in letter-color synesthesia, although the relevance of synesthesia as a psycholinguistic phenomenon has recently been stressed (Simner, 2007). Therefore, the current study was designed to investigate the issue of bidirectionality in the letter-color variant of grapheme-color synesthesia using a word fragment completion paradigm. In front of each word fragment, a color patch was presented replacing the missing first letter of the word. Each word fragment could be completed by only two different first letters, resulting in a German word with a low or high frequency, respectively. The color patch was adjusted individually for each synesthete so that it matched the color associated with the letter which, when used to complete the word, resulted in the low-frequency word. Thus, if color triggers the representation of the letter (i.e., letter-color synesthesia is implicitly bidirectional), synesthetes should retrieve the low-frequency word more often than control subjects without graphemecolor synesthesia, whose lexical search should not be influenced by the color patch. Furthermore, we investigated whether the letter-color synesthetes showed a magnitude distance effect in the current word fragment completion task. The presence of a magnitude distance effect would support the notion that similar interference effects can be observed for synesthetic and nonsynesthetic processing.

\section{METHODS}

\section{Subjects}

Ten female grapheme-color synesthetes with letters (and digits) triggering additional color percepts, and 10 age-matched female control subjects without past or current neurological or psychiatric disease participated in the study. The two subject groups were matched for age (synesthetes $=23.4 \pm 2.2$ years [mean \pm standard deviation], controls $=22.9$ years \pm 2.8 years) and IQ, as assessed by the Multiple Choice Vocabulary Test version B (MWT-B, Lehrl, Triebig, \& Fischer, 1995; synesthetes $=117 \pm 10.2$, controls $=116 \pm 13.2$ ). In addition, there was no significant difference in handedness, as assessed by the Edinburgh Inventory for Handedness (Oldfield, 1971; synesthetes' LQ: $51.9 \pm 70.2$, controls' LQ: $69.3 \pm 41.1$ ). The subjects underwent a neuropsychological test battery comprising the Ishihara (1994) color plates, the Visual Object and Space Perception test battery (Lezak, 1995), and the Short Syndrome-Test (SKT; Lehfeld \& Erzigkeit, 1997). All subjects performed within or above the normal range in these tests.

As in our previous studies (Weiss et al., 2005; Weiss, Shah, Toni, Zilles, \& Fink, 2001), a test of consistency (Baron-Cohen, Harrison, Goldstein, \& Wyke, 1993) was used to verify the presence of genuine synesthesia. All synesthetes were given a 129-item list containing the 26 letters of the alphabet (plus the three German "umlaute": ä, $\ddot{\mathrm{o}}$, and $\ddot{\mathrm{u}}$ ), the digits 0 to 10 , the days of the week, and the names of the 12 months, as well as 10 items of each of the following categories: objects, cities, female names, male names, animals, professions, and abstract nouns. For each of these 129 items, the specific synesthetic color experience of each synesthete was documented. Without forewarning, the list was again given to the synesthetes after at least 6 months $(6.4 \pm 0.4$ months). The color responses of all synesthetes were highly consistent over time (rate of consistent responses: $91.5 \pm 6.9 \%$ ). This rate of consistency in the current group of ten graphemecolor synesthetes is comparable to previous reports (e.g., 92.3\% for 9 synesthetes in Baron-Cohen et al., 1993) and clearly higher than the rate of consistent responses of control subjects even when retested 1 week later (e.g., 37.6\% in Baron-Cohen et al., 1993).

\section{Stimulus Material}

The German words selected for the word fragment completion paradigm had to fulfil two criteria: (i) exchanging the first letter of a given word resulted in a new German word with different meaning (e.g., Turm [tower], Wurm [worm]), and (ii) the frequencies as assessed by the CELEX database (Baayan, Piepenbrock, \& Gulikers, 1993) of the two resulting German words had to be markedly different. The CELEX database contains about 52,000 German words and their corresponding relative frequencies $(F)$ in written and spoken German language. This relative frequency (occurrences per million, opm) is given in relation to the 6 million tokens in the CELEX database recorded from written text and transcribed speech. For our purposes, a German word with an $F$ around $100 \mathrm{opm}$ was considered a high-frequency word, whereas an $F$ below $50 \mathrm{opm}$ indicated a lowfrequency word (see also Kronbichler et al., 2004).

First of all, 90 German word pairs that differed only in the first letter were selected. For these 90 word pairs, the CELEX database was consulted. Due to different reasons (the frequencies of both words [or of one word] were not listed in the database, were too similar, or too high), only 26 word pairs of the initial set of 90 word 
pairs could be used for the pretest. The purpose of the pretest was to verify the relative frequency of these 26 German word pairs in a group of young women $(n=$ 25 , age $=22.3 \pm 2.8$ years), who were all native speakers of German. These women were presented with a written list of the 26 word fragments corresponding to the 26 word pairs (without the first letter) and were asked to add the first letter to each word fragment to create a proper German word. The pretest revealed that for 11 of the 26 preselected word pairs, the judgment of the 25 young women was inconsistent with the CELEX database (e.g., Suche [search]: CELEX: 151 opm, pretest: 4 of 25; Buche [beech tree]: CELEX: 22 opm, pretest: 21 of 25) or did not reveal a similarly strong frequency difference as in the CELEX database (e.g., Wiese [meadow]: CELEX: 125 opm, pretest: 14 of 25; Riese [giant]: CELEX: 40 opm, pretest: 11 of 25). Thus, a final list of 15 word pairs was established for the proper experiment (see Table 1). The resulting German words were all nouns in their singular form: No foreign words or proper names were included.

During the test of consistency, the individual colors for all 26 letters of the alphabet were recorded for all 10 grapheme-color synesthetes. Furthermore, the individual RGB values corresponding to the color of the task-relevant letters (initial letters of the high- and lowfrequency words; i.e., B, G, H, J, K, L, M, N, R, S, T, and
W), as well as those of 10 randomly chosen distractor letters, were determined for each synesthetic woman. Synesthetes were asked to color the capital letters presented on a computer monitor (with the help of Microsoft Word) in a color that matched their synesthetic photism for this particular grapheme as closely as possible. The corresponding RGB values were documented and used for the programming of the experimental stimuli (colored squares in front of the word fragments; see below). Just before the experimental session, synesthetic subjects had to verify the previously documented RGB values. All 10 synesthetes correctly recognized the displayed colors as their synesthetic colors for each letter. In only two cases, the RGB values were slightly adjusted by the synesthetes to ensure proper visual presentation of their individual colors during the experiment.

\section{Experimental Procedure and Paradigm}

Synesthetes and control subjects were comfortably seated in front of a computer monitor. A microphone connected to a Voicekey SV-1 (Cedrus, California, USA) was used for recording the verbal responses and the corresponding reaction times. Using the software Presentation (Version 9.81; Neurobehavioral Systems, California, USA),

Table 1. List of the 15 Used Word Fragments, the Corresponding High-frequency and Low-frequency German Words, and Their English Translations (in Parentheses)

\begin{tabular}{|c|c|c|c|c|}
\hline Word Fragment & High-frequency Word & $\begin{array}{c}\text { F of High-frequency } \\
\text { Word (opm) }\end{array}$ & Low-frequency Word & $\begin{array}{c}\text { F of Low-frequency } \\
\text { Word (opm) }\end{array}$ \\
\hline _agel & Nagel (nail) & 74 & Hagel (hail) & 11 \\
\hline _eiz & Reiz (appeal) & 79 & Geiz (avarice) & 6 \\
\hline _agd & Jagd (hunt) & 99 & Magd (maid) & 26 \\
\hline atze & Katze (cat) & 105 & Tatze (paw) & 3 \\
\hline _rille & Brille (glasses) & 106 & Grille (cricket) & 6 \\
\hline _olke & Wolke (cloud) & 135 & Molke (whey) & 1 \\
\hline _antel & Mantel (coat) & 157 & Hantel (dumbbell) & 4 \\
\hline _upfer & Kupfer (copper) & 165 & Tupfer (swab) & 3 \\
\hline _öwe & Löwe (lion) & 251 & Möwe (seagull) & 43 \\
\hline _old & Gold (gold) & 286 & Sold (pay) & 4 \\
\hline _ette & Kette (chain) & 137 & Wette (bet) & 43 \\
\hline rab & Grab (grave) & 262 & Trab (trot) & 10 \\
\hline _iete & Miete (rent) & 199 & Niete (blank) & 10 \\
\hline _ühne & Bühne (stage) & 337 & Sühne (atonement) & 17 \\
\hline _üge & Lüge (lie) & 192 & Rüge (reproval) & 21 \\
\hline Mean $(S D)$ & & $172.3(80.6)$ & & $13.9(13.8)$ \\
\hline
\end{tabular}

$\mathrm{opm}=$ occurrences per million; $S D=$ standard deviation 
the word fragments (e.g., "iete") were presented in the center of the computer monitor. Left of each word fragment, that is, replacing the first letter of the word, a square was presented which was colored (using the previously documented RGB values) according to the individual synesthetes' photism triggered by the letter (e.g., "N") which completed the word stem to the lowfrequency word (e.g., "Niete"; see Figure 1). Subjects were instructed to complete the word fragment as spontaneously and as quickly as possible, thereby producing a German word. Before the experiment, all subjects were familiarized with the procedure and the task using the presentation of word fragments with similar frequency (see above) and squares colored in black. Nevertheless, in some cases ( $n=9$ of 300 trials total), subjects were unable to retrieve a proper German word corresponding

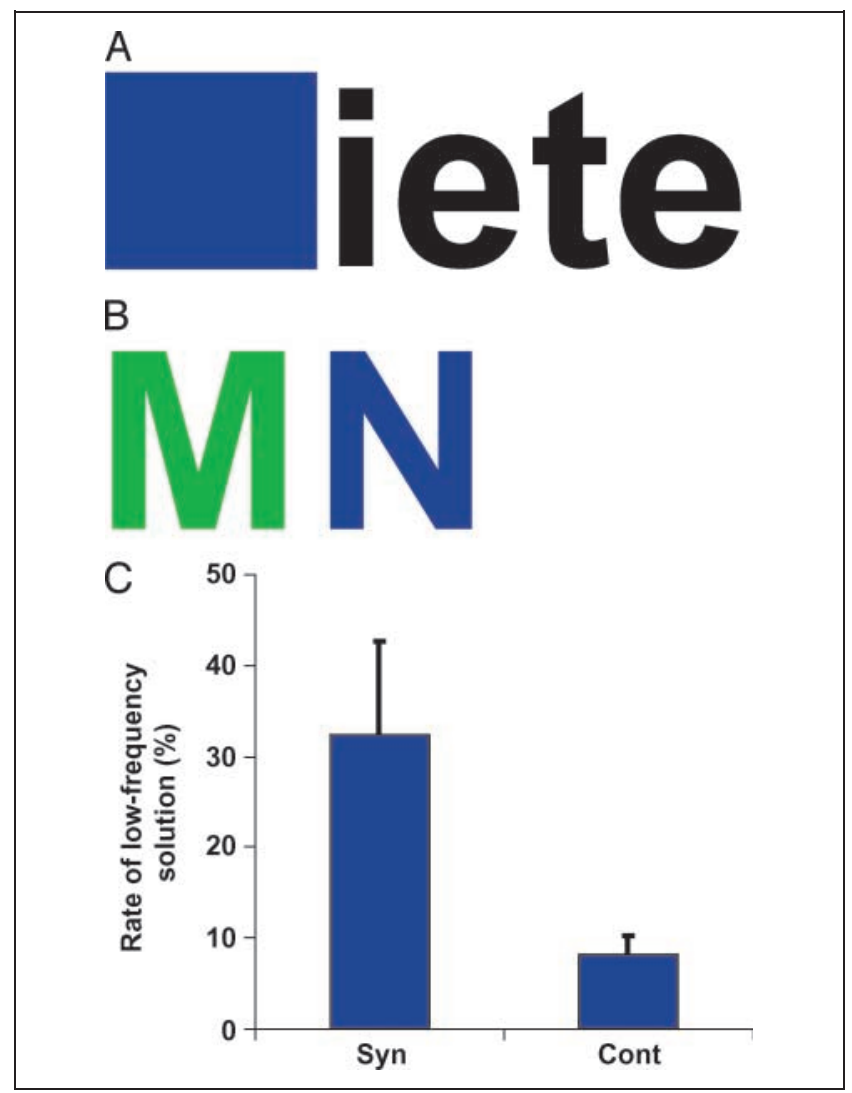

Figure 1. (A) Example stimulus. A colored square is presented together with the word fragment "iete." Note that the square is colored according to the colored photism corresponding to the letter " $\mathrm{N}$ " for the synesthete A. C. (see also B). (B) Illustration of the colored photisms corresponding to the letters "M" (green) and "N" (blue) of the synesthete A. C. (C) Significant difference in the rate of producing the low-frequency word (in \%) between the synesthetes (Syn, $n=10$ ) and the control subjects (Cont, $n=10$ ). When presented with a colored square (in front of the word fragment) corresponding to the letter, for example, "N," completing the word fragment to a low-frequency German word, for example, "Niete" (blank), grapheme-color synesthetes are significantly more influenced in their lexical search than control subjects, who more often produce-as expected-the high-frequency word, for example, "Miete" (rent). to the word fragment. These individual cases were excluded from further analysis.

Each of the 15 word fragments was presented for $8 \mathrm{sec}$ with an interstimulus interval of 2 sec (blank screen). For each synesthete, an individual presentation sequence was created. These individual sequences were also used for each matched control subject. The following restrictions applied when creating the individual trial sequences: (i) a possible target letter should not be repeated in two consecutive trials (e.g., G, resulting in two low-frequency words [Geiz, Grille] or $\mathbf{M}$, resulting in a low-frequency and a high-frequency word [Möwe, Miete]); (ii) a given color should not be repeated in two consecutive trials [given (i), this could only happen when a synesthete reported similarly colored photisms for different letters]; and (iii) word fragments corresponding to words with a related meaning (e.g., "old" [Gold, gold] and "upfer" [Kupfer, copper] or "atze" [Katze, cat] and "öwe" [Löwe, lion]) should not follow each other to prevent semantic priming. These restrictions minimized any priming effects other than the intended priming of letters by the colored square in the synesthetes.

\section{Debriefing}

Directly after completion of the experiment, the graphemecolor synesthetes were asked whether the colored squares elicited the explicit perception of the associated letters. Triggered by the comments of the reviewers, a second debriefing was performed asking the grapheme-color synesthetes whether they had used the explicit strategy of converting the color into its corresponding letter to solve the word fragment completion task. Furthermore, the grapheme-color synesthetes were asked whether they could report the letter associated with a given color to test for potential explicit memories of their synesthetic letter-color associations.

\section{Data Analysis}

If the lexical search of the grapheme-color synesthetes was influenced by the colored squares in front of the word fragments, they should name the low-frequency words significantly more often than control subjects, who (not being influenced by the colored squares) should, contrarily, produce the high-frequency words (Jescheniak \& Levelt, 1994). Accordingly, the rate of naming the lowfrequency word as the ratio between the number of produced low-frequency words and the overall number of correctly retrieved German words triggered by the 15 word fragments was determined for each subject. Then, the rates of naming the low-frequency words were compared between the two subject groups using a two-sample $t$ test. Similarly, the reaction times of the grapheme-color synesthetes and the control subjects during the performance 
of the word fragment completion task were analyzed using a two-sample $t$ test.

\section{RESULTS}

The rate of producing the low-frequency word was significantly higher for grapheme-color synesthetes (mean \pm standard deviation: $32.3 \pm 10.3 \%$ ) than for control subjects $[8.2 \pm 1.9 \%, t(18)=2.31, p<.05$; see Figure $1 \mathrm{C}]$. The reaction times of the grapheme-color synesthetes (mean \pm standard deviation: $1.713 \pm 0.483 \mathrm{sec}$ ) and the control subjects $(1.517 \pm 0.463 \mathrm{sec})$ did not differ significantly $[t(18)=0.902, n s]$.

Based on these results, a possible magnitude distance effect was examined. In the classic size congruency paradigm, interference occurs between the physical size of a digit and its numerical value, for example, 24 (Cohen Kadosh et al., 2005). Furthermore, performance in the classical size congruency paradigm is influenced by the magnitude distance effect: Subjects can compare two stimuli faster when the distance between them is large (Moyer \& Landauer, 1967). For example, the chances for the irrelevant physical size to interfere with numerical processing are smaller, the larger the numerical distance is, e.g., 2 9. With regard to the current paradigm, the effect of the task-irrelevant color patch on the lexical search of grapheme-color synesthetes should be smaller when the frequency distance between the low-frequency and the high-frequency words corresponding to a given word fragment is large, for instance, _rab, Trab (trot, $F$ of $10 \mathrm{opm}$ ) and Grab (grave, $F$ of 262 opm; see Table 1 ). In contrast, the smaller the frequency distance between the low-frequency and high-frequency words, the greater the chances that the color patch will influence the lexical search of the grapheme-color synesthetes, for example,_agd, Magd (maid, $F$ of 26 opm) and Jagd (hunt, $F$ of 99 opm; see Table 1). However, psychophysical research on size perception and magnitude coding suggests that parameters such as word frequency are not represented in a linear fashion; rather the perceived distance between frequencies is better expressed in logarithmic terms (e.g., Fechner-Weber law and Stevens' law; Nieder \& Miller, 2003; Johnson, Hsiao, \& Yoshioka, 2002). Following this notion, a frequency distance of $10 \mathrm{opm}$ in the low-frequency range (e.g., 20 vs. $30 \mathrm{opm}$ ) would correspond to a (perceived) frequency distance of $100 \mathrm{opm}$ in the high-frequency range (i.e., 200 vs. $300 \mathrm{opm}$ rather than 200 vs. $210 \mathrm{opm}$ ). Therefore, the frequency of each word (as derived from the CELEX database) was logarithmically transformed and then the mean corrected frequency distance was computed for all word pairs. Afterwards, the 15 word pairs were divided into two groups, with a mean corrected frequency distance below or above average. With the help of a $t$ test, it was then examined whether in grapheme-color synesthetes the production of low-frequency words occurred more often for the word pairs with a small mean cor- rected frequency distance in comparison to the word pairs with a large mean corrected frequency distance. This magnitude distance effect analysis based on the logarithmically transformed word frequencies revealed that grapheme-color synesthetes produced low-frequency words more often for the word pairs with a small mean corrected frequency distance $(38.6 \pm 4.2 \%)$ than for the word pairs with a large mean corrected frequency distance $[19.6 \pm 3.7 \%, t(13)=2.40, p<.05]$.

Finally, in the postexperimental debriefing, none of the grapheme-color synesthetes reported that the colored squares evoked an explicit perception of the associated letters during the experiment. Furthermore, the grapheme-color synesthetes denied that they had used the strategy of converting the color into its corresponding letter to solve the word fragment completion task. However, most of the grapheme-color synesthetes were able to report the letter associated with a given color.

\section{DISCUSSION}

When primed with the appropriate color in the current word fragment completion paradigm, grapheme-color synesthetes with letter-color synesthesia produced lowfrequency words significantly more often than nonsynesthetic control subjects. This suggests that in letter-color synesthesia, an implicit activation of the letter representation can be elicited by the color which corresponds to the colored synesthetic photism associated with that letter. In line with previous studies investigating the directionality of digit-color synesthesia (Knoch et al., 2005; Cohen Kadosh et al., 2005; Brugger et al., 2004) and ordinal linguistic personification (Simner \& Holenstein, 2007; Simner \& Hubbard, 2006), the current data support the notion that synesthesia is-at least at an implicit level of processing - bidirectional and show, for the first time, that this bidirectionality in grapheme-color synesthesia is not confined to numerical processing, but can also influence lexical processing.

Recently, Cohen Kadosh and Henik (2007) suggested that bidirectionality in synesthesia may occur to different degrees. These authors distinguish between (i) nonsynesthetes, who may behave like synesthetes (e.g., mental number line); (ii) unidirectional synesthetes without bidirectionality; (iii) unidirectional synesthetes with implicit bidirectionality; and (iv) "unidirectional" synesthetes with explicit bidirectionality (p. 179). Following this classification, the grapheme-color synesthetes $(n=10)$ in our study are unidirectional synesthetes, whose letter-color synesthesia is implicitly bidirectional. In the debriefing, the grapheme-color synesthetes denied that the colored squares on the monitor triggered the explicit perception of the associated letter. Furthermore, they did not use the strategy of explicitly converting the color into its corresponding letter to solve the word fragment completion task. That synesthetes showed 
findings akin to a distance effect in the word frequency domain argues against the idea that they were strategically using the color to complete the word fragments. If synesthetes were using this strategy, they would have generated an equivalent amount of low-frequency words when word pairs were either close or discrepant in word frequency. In addition, the similar reaction times of the grapheme-color synesthetes and control subjects suggest that both groups actually performed lexical search during the word fragment completion task. However, consistent with previous reports, most of the graphemecolor synesthetes could overtly report which letter was associated with a given color (e.g., "N" is blue), suggesting that they have an explicit memory of their individual letter-color associations. Therefore, we cannot exclude that these memories have influenced the task performance of the grapheme-color synesthetes in the current study even if they denied that they have used an explicit color-to-letter conversion strategy to solve the task and performed the task with similar reaction times as nonsynesthetic controls. Future studies are needed to further disentangle whether bidirectional processing of colors and letters in letter-color synesthesia is due to explicit memories of letter-color associations or true implicit perception.

It should be noted that with the exception of the study by Knoch et al. (2005), who examined the bidirectionality of digit-color synesthesia in 20 synesthetes, previous studies on bidirectional processing in synesthesia are mainly case studies. Thus, our sample of 10 synesthetes constitutes the second largest group of synesthetes with experimentally confirmed implicit bidirectionality. Furthermore, our study shows bidirectional processing for letters rather than digits. This suggests that bidirectional processing in synesthesia is not confined to a certain type of synesthesia (e.g., digit-color synesthesia), but rather, represents a general feature of synesthesia (Cohen Kadosh \& Henik, 2007; Simner \& Hubbard, 2006). Current theories of the cognitive and neurobiological mechanisms underlying synesthesia (Cohen Kadosh \& Henik, 2007; Hubbard, 2007; Hubbard \& Ramachandran, 2005; Grossenbacher \& Lovelace, 2001) should take into account the growing evidence that synesthesia is bidirectional and multidimensional, at least implicitly.

Many studies over the last years have provided evidence that synesthesia can modulate conceptual as well as perceptual processing (for a review, see Rich \& Mattingley, 2002). Similar to nonsynesthetic percepts, synesthetic experiences can both facilitate (Hubbard, Arman, Ramachandran, \& Boynton, 2005; Palmeri, Blake, Marios, Flanery, \& Whetsell, 2002) and interfere with stimulus processing (e.g., synesthetic Stroop effect; Banissy \& Ward, 2007; Beeli, Esslen, \& Jäncke, 2005; Mattingley et al., 2001; Dixon, Smilek, Cudahy, \& Merikle, 2000). Furthermore, bidirectional synesthetic experiences (e.g., digit representations triggered by colors) may lead to interference (Cohen Kadosh \& Henik, 2006b) or facilitation (Cohen Kadosh et al., 2005). In the current study on bidirectionality in the letter-color variant of grapheme-color synesthesia, the task-irrelevant colors significantly influenced the lexical search of the synesthetes so that they retrieved the low-frequency rather than the more common high-frequency word corresponding to the word fragment. From psychophysical studies of nonsynesthetic numerical processing, it is known that such influences of task-irrelevant information are modulated by the magnitude distance effect (Schwarz \& Ischebeck, 2003; Moyer \& Landauer, 1967). For the implicit activation of the letter representation by the task-irrelevant color, we also observed here a magnitude distance effect in letter-color synesthesia when using logarithmically transformed word frequencies. There was significantly less influence of color on the lexical search of grapheme-color synesthetes when the word frequency distance was large compared to a small difference between word frequencies (see also Cohen Kadosh \& Henik, 2006a). Thus, similar effects can be observed for nonsynesthetic and synesthetic numerical and lexical processing.

The accumulating data on the bidirectionality of synesthesia raise the question where in the brain the reciprocal activation of color and grapheme (or digit) representations occurs. There is converging evidence from functional (Weiss et al., 2005) and structural (Rouw \& Scholte, 2007; Weiss \& Fink, in press) MRI studies, as well as TMS studies (Muggleton, Tsakanikos, Walsh, \& Ward, 2007; Esterman, Verstynen, Ivry, \& Robertson, 2006) that parietal cortex may play an important role in synesthesia (Hubbard, 2007; Mulvenna \& Walsh, 2006). Interestingly, parietal cortex is also implicated in the interaction between numerical processing and the processing of physical properties, such as size (Pinel, Piazza, Le Bihan, \& Dehaene, 2004) and luminance (Cohen Kadosh, Cohen Kadosh, \& Henik, 2008), in nonsynesthetes. Importantly, parietal cortex is also involved in color processing (Gulyas \& Roland, 1991). Finally, a representation of letters was recently found in parietal cortex (Fias, Lammertyn, Caessens, \& Orban, 2007). Thus, parietal cortex endowed with these manifold representations seems to be ideally suited to allow for bidirectional interactions of color, digit, and letter representations, and may thus constitute the neural locus where bidirectional synesthesia occurs. This notion has been recently supported by a functional imaging case study on I. S., an explicit bidirectional synesthete (Cohen Kadosh et al., 2007). Interestingly, Simner and Hubbard (2006) also propose that parietal cortex links ordinal sequences, personalities, and colors in A. P., a woman with grapheme-color synesthesia and ordinal linguistic personification.

The two-stage model of synesthesia (Hubbard, 2007) proposes that synesthetic experiences may arise from abnormal cross-activation between the grapheme area 
and the color area in the fusiform gyrus due to altered local connections. The synesthetic color perceptions generated in the fusiform gyrus are then bound together by parietal mechanisms resulting in a kind of "hyperbinding." According to this model, bidirectional synesthetic experiences can occur at different levels, namely, at the level of the fusiform gyrus (a lower-tier area) or at the level of parietal cortex (a higher-tier area; see also Cohen Kadosh et al., 2007). As previous studies showed that TMS can interfere with the binding of graphemes and colors in grapheme-color synesthesia (Muggleton et al., 2007; Esterman et al., 2006), future research needs to show whether TMS applied above parietal cortex will also interfere with bidirectional effects on numerical and lexical processing by color in the digit-color or lettercolor variants of grapheme-color synesthesia.

\section{Acknowledgments}

We thank Dr. Stefan Heim for many helpful suggestions during the preparation of this study. G. R. F. was supported by the DFG (KFO-112, TP1). Additional support by the Medical Faculty of the RWTH Aachen (rotation programme) to P. H. W. is gratefully acknowledged. Finally, we thank both reviewers for their constructive criticism on an earlier version of the manuscript.

Reprint requests should be sent to Peter H. Weiss, Cognitive Neurology, Institute of Neuroscience and Biophysics-Medicine (INB-3), Research Centre Jülich, 52425 Jülich, Germany, or via e-mail: P.H.Weiss@fz-juelich.de.

\section{REFERENCES}

Baayan, R. H., Piepenbrock, R., \& Gulikers, L. (1993). The CELEX lexical database. University of Pennsylvania, Philadelphia, PA: Linguistic Data Consortium.

Banissy, M. J., \& Ward, J. (2007). Mirror-touch synesthesia is linked with empathy. Nature Neuroscience, 10, 815-816.

Baron-Cohen, S., Harrison, J., Goldstein, L., \& Wyke, M. A. (1993). Coloured speech perception: Is synaesthesia what happens when modularity breaks down. Perception, 22, 419-426.

Beeli, G., Esslen, M., \& Jäncke, L. (2005). When coloured sounds taste sweet. Nature, 434, 28.

Brugger, P., Knoch, D., Mohr, C., \& Gianotti, L. R. R. (2004). Is digit-color synaesthesia strictly unidirectional? Preliminary evidence for an implicitly colored number space in three synaesthetes. Acta Neuropsychologica, 2, 252-258.

Callejas, A., Acosta, A., \& Lupianez, J. (2007). Green love is ugly: Emotions elicited by synesthetic grapheme-color perceptions. Brain Research, 1127, 99-107.

Cohen Kadosh, R., Cohen Kadosh, K., \& Henik, A. (2007). The neuronal correlate of bidirectional synesthesia: A combined event-related potential and functional magnetic resonance imaging study. Journal of Cognitive Neuroscience, 19, 2050-2059.

Cohen Kadosh, R., Cohen Kadosh, K., \& Henik, A. (2008). When brightness counts: The neuronal correlate of numerical-luminance interference. Cerebral Cortex, 18, 337-343.

Cohen Kadosh, R., \& Henik, A. (2006a). Color congruity effect: Where do colors and numbers interact in synesthesia? Cortex, 42, 259-263.

Cohen Kadosh, R., \& Henik, A. (2006b). When a line is a number: Color yields magnitude information in a digit-color synesthete. Neuroscience, 137, 3-5.

Cohen Kadosh, R., \& Henik, A. (2007). Can synaesthesia research inform cognitive science? Trends in Cognitive Sciences, 11, 177-184.

Cohen Kadosh, R., Sagiv, N., Linden, D. E. J., Robertson, L. C., Elinger, G., \& Henik, A. (2005). When blue is larger than red: Colors influence numerical cognition in synaesthesia. Journal of Cognitive Neuroscience, 17, 1766-1773.

Dehaene, S. (1992). Varieties of numerical abilities. Cognition, 44, 1-42.

Dixon, M. J., Smilek, D., Cudahy, C., \& Merikle, P. M. (2000). Five plus two equals yellow. Nature, 406, 365.

Esterman, M., Verstynen, T., Ivry, R. B., \& Robertson, L. C. (2006). Coming unbound: Disrupting automatic integratin of synaesthetic color and graphemes by transcranial magnetic stimulation of the right parietal lobe. Journal of Cognitive Neuroscience, 18, 1570-1576.

Fias, W., Lammertyn, J., Caessens, B., \& Orban, G. A. (2007). Processing of abstract ordinal knowledge in the horizontal segment of the intraparietal sulcus. Journal of Neuroscience, 27, 8952-8956.

Grossenbacher, P. G., \& Lovelace, C. T. (2001). Mechanisms of synesthesia: Cognitive and physiological constraints. Trends in Cognitive Sciences, 5, 36-41.

Gulyas, B., \& Roland, P. E. (1991). Cortical fields participating in form and colour discrimination in the human brain. NeuroReport, 2, 585-588.

Hubbard, E. M. (2007). Neurophysiology of synesthesia. Current Psychiatry Reports, 9, 193-199.

Hubbard, E. M., Arman, A. C., Ramachandran, V. S., \& Boynton, G. M. (2005). Individual differences among grapheme-color synesthetes: Brain-behavior correlations. Neuron, 45, 975-985.

Hubbard, E. M., \& Ramachandran, V. S. (2005). Neurocognitive mechanisms of synesthesia. Neuron, 48, 509-520.

Ishihara, S. (1994). Ishihara's tests for colour blindness. Tokyo: Kanehara \& Co

Jescheniak, J. D., \& Levelt, W. J. M. (1994). Word frequency effects in speech production: Retrieval of syntactic information and of phonological form. Journal of Experimental Psychology: Learning, Memory, and Cognition, 20, 824-843.

Johnson, K. O., Hsiao, S. S., \& Yoshioka, T. (2002). Neural coding and the basic law of psychophysics. The Neuroscientist, 8, 111-121.

Knoch, D., Gianotti, L. R. R., Mohr, C., \& Brugger, P. (2005). Synesthesia: When colors count. Cognitive Brain Research, 25, 372-374.

Kronbichler, M., Hutzler, F., Wimmer, H., Mair, A., Staffen, W., \& Ladurner, G. (2004). The visual word form area and the frequency with which words are encountered: Evidence from a parametric fMRI study. Neuroimage, 21, 946-953.

Lehfeld, H., \& Erzigkeit, H. (1997). The SKT—A short cognitive performance test for assessing deficits of memory and attention. International Psychogeriatrics, 9, 115-121.

Lehrl, S., Triebig, G., \& Fischer, B. (1995). Multiple choice vocabulary test MWT as a valid and short test to estimate premorbid intelligence. Acta Neurologica Scandinavica, 91, 335-345.

Lezak, M. D. (1995). Neuropsychological assessment (3rd ed.). Oxford: Oxford University Press.

Mattingley, J. B., Rich, A. N., Yelland, G., \& Bradshaw, J. L. (2001). Unconscious priming eliminates automatic binding of colour and alphanumeric form in synaesthesia. Nature, 410, 580-582. 
Moyer, R. S., \& Landauer, T. K. (1967). Time required for judgment of numerical inequality. Nature, 215, $1519-1520$.

Muggleton, N., Tsakanikos, E., Walsh, V., \& Ward, J. (2007). Disruption of synaesthesia following TMS of the right posterior parietal cortex. Neuropsychologia, 45, 1582-1585.

Mulvenna, C., \& Walsh, V. (2006). Synaesthesia: Supernormal integration? Trends in Cognitive Sciences, 10, 350-352.

Nieder, A., \& Miller, E. K. (2003). Coding of cognitive magnitude: Compressed scaling information in the primate prefrontal cortex. Neuron, 37, 149-157.

Oldfield, R. C. (1971). The assessment and analysis of handedness: The Edinburgh Inventory. Neuropsychologia, 9, 97-113.

Palmeri, T. J., Blake, R., Marios, R., Flanery, M. A., \& Whetsell, W. (2002). The perceptual reality of synesthetic colors. Proceedings of the National Academy of Sciences, U.S.A., 99, 4127-4131.

Pinel, P., Piazza, M., Le Bihan, D., \& Dehaene, S. (2004). Distributed and overlapping cerebral representations of number, size, and luminance during comparative judgments. Neuron, 41, 983-993.

Rich, A. N., \& Mattingley, J. B. (2002). Anomalous perception in synaesthesia: A cognitive neuroscience perspective. Nature Reviews Neuroscience, 3, 43-52.

Rouw, R., \& Scholte, H. S. (2007). Increased structural connectivity in grapheme-color synesthesia. Nature Neuroscience, 10, 792-797.
Schwarz, W., \& Ischebeck, A. (2003). On the relevant speed account of the number-size interference in comparative judgments of numerals. Journal of Experimental Psychology: Human Perception and Performance, 29, 507-522.

Simner, J. (2007). Beyond perception: Synaesthesia as a psycholinguistic phenomenon. Trends in Cognitive Sciences, 11, 23-29.

Simner, J., \& Holenstein, E. (2007). Ordinal linguistic personification as a variant of synesthesia. Journal of Cognitive Neuroscience, 19, 694-703.

Simner, J., \& Hubbard, E. M. (2006). Variants of synaesthesia interact in cognitive tasks: Evidence for implicit associations and late connectivity ion cross-talk theories. Neuroscience, 143, 805-814.

Simner, J., Mulvenna, C., Sagiv, N., Tsakanikos, E., Witherby, S. A., Fraser, C., et al. (2006). Synaesthesia: The prevalence of atypical cross-modal experiences. Perception, 35, 1024-1033.

Weiss, P. H., \& Fink, G. R. (in press). Grapheme-colour synaesthetes show increased gray matter volumes of parietal and fusiform cortex. Brain.

Weiss, P. H., Shah, N. J., Toni, I., Zilles, K., \& Fink, G. R. (2001). Associating colours with people: A case of chromatic-lexical synaesthesia. Cortex, 37, 750-753.

Weiss, P. H., Zilles, K., \& Fink, G. R. (2005). When visual perception causes feeling: Enhanced crossmodal processing in grapheme-color synesthesia. Neuroimage, 28, 859-868. 
Copyright of Journal of Cognitive Neuroscience is the property of MIT Press and its content may not be copied or emailed to multiple sites or posted to a listserv without the copyright holder's express written permission. However, users may print, download, or email articles for individual use. 